Int. J. Electrochem. Sci., 14 (2019) 10490 - 10507

\title{
Corrosion Behavior of Waterborne Epoxy Ester Coatings with Different Composition in NaCl Solution
}

\author{
Zhendong Sun ${ }^{1,2,3, *}$, Lina Zhao ${ }^{2}$, Yong Guan ${ }^{2}$, Qiushi Song ${ }^{1}$, Qian Xu ${ }^{1,4}$, Chuanwei Yan ${ }^{3}$ \\ ${ }^{1}$ School of Metallurgy, Northeastern University, Shenyang 110819, China; \\ ${ }^{2}$ Shenyang Institute of Engineering, Shenyang 110136, China; \\ ${ }^{3}$ Laboratory for Corrosion and Protection of Metals, Institute of Metal Research, Chinese Academy of \\ Sciences, Shenyang 110016, China; \\ ${ }^{4}$ State Key Laboratory of Advanced Special Steel, School of Materials Science and Engineering, \\ Shanghai University, Shanghai 200072, China \\ *E-mail: sunzd@sie.edu.cn
}

doi: $10.20964 / 2019.11 .37$

Received: 1 July 2019 / Accepted: 26 August 2019 / Published: 7 October 2019

In this paper, the effect of water resistance, crosslinking degree, pigments addition, and immersion time on corrosion behavior of the waterborne epoxy ester coatings with different composition in 3.5 wt.\% $\mathrm{NaCl}$ solution have been studied by electrochemical impedance spectroscopy (EIS). Results show that the coating of higher water resistance and crosslinking degree has higher corrosion resistance. However, much higher crosslinking degree may lead to decreased water resistance of the coating, and it is necessary to minimize the content of hydrophilic groups in the waterborne coating while ensuring a qualified crosslinking degree for improving its corrosion resistance. The waterborne epoxy ester varnish coating without pigments addition degrades quickly in $\mathrm{NaCl}$ solution compared with the coating with pigments addition of $\mathrm{ZnMoO}_{4}$ and $\mathrm{Zn}_{3}\left(\mathrm{PO}_{4}\right)_{2}$. For the corrosion evolution of waterborne epoxy ester coating in $\mathrm{NaCl}$ solution, it has better shielding effect at $6 \mathrm{~h}$ immersion. At 72 $\mathrm{h}$ immersion, it still has corrosion protection effect to steel substrate; the $\mathrm{NaCl}$ electrolyte has penetrated into the coating but has not reached the coating/substrate interface. At $120 \mathrm{~h}$ immersion time, $\mathrm{NaCl}$ electrolyte has reached the coating/steel interface, and the steel corrosion has occurred. At $240 \mathrm{~h}$ immersion time, serious corrosion attack has occurred on the steel substrate, and the waterborne epoxy ester coating has lost its shielding effect and corrosion protection effect to the underlying steel substrate.

Keywords: Waterborne coating; Epoxy ester coating; Corrosion behavior; $\mathrm{NaCl}$ solution; Shielding effect

\section{$\underline{\text { FULL TEXT }}$}


(C) 2019 The Authors. Published by ESG (www.electrochemsci.org). This article is an open access article distributed under the terms and conditions of the Creative Commons Attribution license (http://creativecommons.org/licenses/by/4.0/). 